Revista Iberoamericana. Vol. LXII, Núms. 176-177, Julio-Diciembre 1996; 941-952

\title{
EL DESCENTRAMIENTO DE LO POSMODERNO
}

\author{
POR \\ Ellen SpielmanN \\ Freie Universität Berlin
}

Existe hoy un consenso acerca de que el Anti-Oedipe de Gilles Deleuze y Félix Guattari fue el primer gran libro de teoría postmoderna. Pero el estilo de su presentación, con la tapa en blanco, el logotipo de la colección "Critique" arriba en azul y la tipografía en negro, según el modelo tradicional introducido por Gallimard desde los años cuarenta, no indica en los más mínimo lo nuevo, el cambio que ha tenido lugar. Sin embargo, esto no asombraba a nadie en 1972. Algún tiempo después, en editoriales reputadas y en las editoras universitarias en los Estados Unidos, comezaron a aparecer una amplia serie de publicaciones que en su outfit se proclamaban "posmodernas". Las dos muestras experimentales tardío-modernas por excelencia en América Latina son El último round de Julio Cortázar y Constelaciones de Haroldo de Campos. El libro de Carlos Rincón La no simultaneidad de lo simultáneo. Posmodernidad, globalizacióny culturas en América Latina (Bogotá: Editorial Universidad Nacional, 1995) es uno de los primeros libros latinoamericanos "posmodernos". Ya su papel, su tipografia, las ilustraciones y los colores, criterios que toma de Neville Brody, ${ }^{1}$ señalan cambios notorios. No sólo el título despierta expectativas e irritaciones, la presentación visual sí que irrita y choca. Esto es válido sobre todo para las imágenes "trabajadas" con computadora en lila, naranja, rojo y verde chillones, para las que no vale, en cambio, el término "ilustraciones". Se trata tanto de fotografías arquitectónicas del emblema de Bogotá, las Torres del Parque de Rogelio Salmona (1972), como de "El arcángel San Miguel, rodeado de cuerpos celestiales y con personificación de nueve órdenes de ángeles, vence a Lucifer", de Martin de Vos (Siglo XVI), "El Símbolo de la Santísima Trinidad (Señor de Gran Poder)" de Arce y Ceballos (Siglo XVII) y el "Portrait of Bungeree" (1991) de Juan Dávila. ¿Qué es lo inquietante de esas imágenes? Quizá no tanto el choque visual mismo, sino el encontrarnos inmersos repentinamente en una discoteca, el sitio en donde, según Umberto Eco, debe estar hoy el filósofo. Aquí no solamente hay un acercamiento estrecho a las formas representativas de la actual cultura global como screenplay y videoclip. Culturas emergentes, como las nuevas culturas urbanas están presentes así en el libro y se asume el desafio de una confrontación directa. Es notable entonces que en este trabajo el interés por el campo relativamente nuevo de la emergente cultura masiva

\footnotetext{
' The Graphic Language of Neville Brody. Text and Captations by Jon Wolencroft (Londres: Victoria and Albert Museum, 1988) 88.
} 
urbana sea actuante, no se lo ponga de lado, como ocurre con otros libros recientes que pertenecen al nuevo canon teórico.

¿Qué tenemos ante nosotros? Éste no es solamente un libro que habla de la urgencia del cambio de los términos del debate modernidad-posmodernidad. No permanece en la realización de ese cambio de paradigmas, un paso que fue tan importante en la segunda parte de los años ochenta y que hasta hoy se sigue celebrando en diversos campos como gran acontecimiento. ${ }^{2}$ Tampoco se queda en la genealogía o en la descripción de la situación y su preocupación no es proporcionar la vigésimo quinta redefinición substancial del posmodernismo. La no simultaneidad de lo simultáneo no es, además, otro libro en la biblioteca internacional sobre el tema del proceso de globalización, que pone en el centro la cuestión de la modernidad ${ }^{3} \mathrm{o}$ del posmodernismo. ${ }^{4}$ Todos estas definiciones negativas no quieren decir, finalmente, que encontremos un nuevo guru, ya que sabemos que pasó el tiempo de los gurús. ¿Qué consigue entonces el libro? Dicho en una frase: el libro descentra el debate sobre lo posmoderno. Lo notable es que aquí - y esa es una especialidad de los trabajos de Carlos Rincón- se construyen puentes entre muy distintos debates en las más distintas disciplinas. Se desarrolla un diálogo tanto entre literatura y las ciencias sociales y humanas como con las ciencias de la comunicación y la teoría. El camino señala, al mismo tiempo, que es un callejón sin salida buscar sus aliados solamente en disciplinas del Siglo XIX: lingüística, psicoanálisis, sociología. La no simultaneidad de lo simultáneo es, diría, el primer libro "posmoderno", una intervención "posmoderna" en que la fijación corriente a la tarea dada -renegociar los debates, relativizarlos o representarlos-es decididamente rebasada. Es "posmoderno" al descentrar esos debates, es decir, en tanto pone de lado planteamientos e interrogaciones que han mostrado ser no produtivos, o los plantea en otra forma $-\mathrm{y}$ sigue adelante.

\section{TítULO - PORTADA}

Gustavo Zalamea es el artista que diseñó la portada. La diagramación y el tratamiento de las "reproduciones" es de Francisco Vásquez. En la portada del libro hay un montaje de imágenes. Una mano (¿masculina? ¿femenina?) en perspectiva sostiene un reloj, un cronómetro de color lila intenso, ante un espacio constituido por un círculo color naranja, en perspectiva, y un círculo amarillo plano con una espiral. A la mano y a los círculos se une, enmarcándolos, un fragmento cartográfico, una parte de un mapa urbano. El mapa no es otro que el Plan Piloto de Bogotá, tal como lo concibió Le Corbusier en 1949: la ciudad disparada, dominada por la velocidad, en expansión. Encima de esas imágenes, el título, que se corresponde con ese montaje. En la inversión de la fórmula de Ernst Bloch — "la simultaneidad de lo no simultáneo"- no se trata de señalar la falta de validez o la insuficiencia de esa ecuación para describir la Modernidad. De esa fórmula que entusiasmó

\footnotetext{
${ }^{2}$ Ver, por ejemplo, Enrique Goneariz Morega/Jorge Vergara Estevez, La crisis teórica de la sociología latinoamericana. Una investigación-reflexión (Santiago: FNICT, sin fecha).

${ }^{3}$ José Joaquín Brunner, Cartografias de la Modernidad (Santiago: Dolmen Ediciones, sin fecha).

${ }^{4}$ Véase Hans Ulrich Gumbrecht y Robert Weimann (eds.), Postmoderne-Globale Differenz (Frankfurt/M: Suhrkamp 1991); David Harvey, The Condition of Postmodernity (Oxford: Basil Blackwell, 1989).
} 
ante todo a los literatos, junto a los críticos y a los científicos sociales latinoamericanos hasta los años setenta, y que fue adoptada como modelo explicatorio para inventar la "especificidad latinoamericana" (Rincón 1995:217). Tampoco se está aludiendo a la complejidad, pluralidad y diversidad de temporalidades sino que, a diferencia del pensamiento posmoderno corriente, se está arriesgándo a otra cosa. ¿A cuál? El sintagma del título es en sí mismo una imagen: su función referencial está asumida como función poética. La naturaleza de esa imagen se deja descomponer en dos momentos. En primer lugar calca un modelo barroco (por ejemplo, el de fórmulas retóricas como "la conveniencia de las inconveniencias") lo que también hacía Bloch, y en esa forma resulta una amalgama semántica. Segundo, la imagen se halla determinada, sobre todo, por su aptitud argumentativa. La representación figurativa (cronómetro-círculos cromáticos-cartografía urbana) funge como visualización particularizadora de la materia tratada (posmodernidad-globalización-culturas en América Latina): relaciones espacio-temporales. Esa imagen hace simbólicamente sensible (en cuanto imagen visual) la idea central. El título (en cuanto imagen con funciones referenciales, poéticas y metacríticas) hace alegóricamente sensible esa misma idea. ¿Cuál es? ¿De qué se trata? Primero: La Modernidad no es destrucción de tradiciones e imposición, en su lugar, de lo moderno (lo Nuevo). Tal vez sea sobre todo nuevas formas de articulación entre el tiempo y el espacio (tempo-espaciales). Pero lo más importante de esa idea central es que esa re-definición de modernidad es ya, podemos decirlo, pos-moderna. Pues lo posmoderno trae una anulación de las barreras de espacio con incremento de las simultaneidades globales. De manera que la segunda idea central que guía el título ya subraya la diferencia frente a los teorizaciones posmodernas: enfocar la no simultaneidad de esas incrementadas simultaneidades globales. Lo decisivo es ver que no se trata simplemente de una cuestión de distintas representaciones, como lo sugieren las teorías posmodernas.

\section{El FINAL DE UN CICLO}

En un ensayo muy inteligente y sensible sobre el libro de Carlos Rincón, Erna von der Walde señaló una paradoja: ese libro era esperado y es al mismo tiempo, completamente inesperado. ${ }^{5}$ Veamos por qué. Entre 1976 y 1979 terminó en Latinoamérica un ciclo literario-cultural que se desarrolló desde los años veinte. Gerald Martin en su libro Journeys through the Labyrinth. Latin American Fiction in the Twentieth Century (1989) fue el primero que comprobó exactamente esa tesis, en la cual venían trabajando algunos críticos. La produción literaria que siguió a Yo el supremo, Terra nostra y El otoño del patriarca mostró no sólo que el boom, asimilado a la alta cultura, había llegado a su fin. Más bien las energías sociales reprimidas entraron dentro de nuevas estrategias en un amplio proceso de "articulación de los márgenes" (de etnia, raza, sexo, clase) de la modernidad periférica. Se anunció un cambio de paradigmas crítico-literarios y teóricos capaz de dar cuenta de las nuevas relaciones entre alta cultura, cultura popular y cultura producida masiva e industrialmente, incluidas en el proceso de articulación de los márgenes.

\footnotetext{
${ }^{5}$ Erna von der Walde, "La no simultaneidad de lo simultáneo de Carlos Rincón", en Montserrat Ordóñez y Claudia Montilla (eds.), Estudios literarios: Relecturas, imaginación y resistencia. Texto $y$ Contexto 28 (1995), 242-257.
} 
Decisivo y verdaderamente nuevo en las publicaciones entre 1978 y 1983 es que el concepto de literatura transcultural y suprahistórico hasta entonces dominante fue superado y de esa manera se hizo posible llegar a situar de manera adecuada el nuevo discurso "literario". En ese sentido el libro de Carlos Rincón El cambio de la noción de literatura y otros estudios de teoría y crítica latinoamericana (1978), representó una revisión crítica de sustantiva importancia. ${ }^{6}$ Pues la vieja función de la literatura como supuesta instancia de mediación y como comunicación entre distintos campos de la sociedad había dejado de funcionar.

Silviano Santiago en Brasil y Antonio Cornejo Polar desde el Perú propusieron, independientemente, concepciones operatorias confluyentes. Santiago acuñó en Una literatura nos trópicos (1978), el concepto del "entre-lugar" de la literatura latinoamericana. Cornejo Polar utilizó en 1980 como concepto analítico lo que hasta ese momento era una noción en circulación: "heterogeneidad". Ambos partían todavía de la idea de "unidad", pero con esas categorías de cuño derrideriano (entre-lugar) y foucaultiano (heterogenidad), propusieron conceptos-palanca para despejar los caminos que bloqueaban las ideas de "síntesis", "mestizaje", "unidad", "transculturación". Otros críticos, como Silvia Molloy en Las letras de Borges (1979) buscaron, con intensiva recepción de los trabajos de Jaques Derrida, nuevas vías productivas y ampliaron las estrategias analíticas. Un libro importante metodológicamente, el intento de construir una teoría del discurso con base en los "actos de lenguaje" de Austin, de Mary Louise Pratt, su Toward a Speech Act Theory of Literary Discourse (1980), circuló en inglés y su impacto en Latinoamérica fue limitado.

En una conferencia dictada en Berlín en 1991 Walter Mignolo destacó los desafíos que planteó Carlos Rincón en su libro sobre El cambio de la noción de literatura: transformación del campo de estudios, apertura hacia los productos de los medios masivos que, entre tanto, "se ha ensanchado a los vastos terrenos de la cultura popular"? A mí se me ocurre que con la superación del concepto transcultural y metahistórico de literatura, el reconocimiento Carlos Rincón destacó, por ejemplo, la importancia del testimonio, a propósito del Cimarrón de Miguel Barnet como un "síntoma" del cambio- suponía que la llamada "alta literatura" (literatura "culta") ya no estaba en el centro de la cultura y que la investigación debía, como lo dice Mignolo acertadamente, determinar de nuevo su objeto y su campo de estudios. Había que redefinir el lugar de la literatura en el campo de la cultura, incluyendo lo que ahora redimensiona ese campo, es decir, la cultura popular urbana, marcada por la presencia de los medios masivos. Pero también se me ocurre que lo que se buscaba era un concepto "posmoderno" de literatura, sin que se llegara a mencionar el término. Me parece muy interesante que Carlos Rincón en 1978 en El cambio de la noción de literatura se rompiera la cabeza sobre ese comienzo tan extraordinario y asombroso de Cien años de soledad. En 1980, dos años después, con el mismo enfoque de Carlos Rincón (problema del incipit en las huellas de Breton), John Barth designa a la novela de García Márquez como

\footnotetext{
${ }^{6}$ Véase John Berverley, Against Literature (Minneapolis/Londres: University of Minnesota Press, 1993) IX.

${ }^{7}$ Véase Walter Mignolo, "Entre el canon y el corpus", en Carlos Rincón y Petra Schumm (eds.), Crítica literaria hoy. Entre las crisis y los cambios:un nuevo escenario. Nuevo Texto Crítico 14-15 (1995) 23.
} 
ficción posmoderna ejemplar en su Manifiesto "The Literature of Replenishment", y celebra ese comienzo como "el gran comienzo" de novela posmoderna.

¿Qué consiguió el debate hasta ese momento? Sobre todo ponerse en camino de superar de manera radical los viejos planteamientos. De ello da cuenta el primer balance de lo que estaba pasando en esos años. Lo hizo Jean Franco en 1981 en una confrontación entre trabajos que se estaba desarrollando entonces en Latinoamérica y en los Estados Unidos, bajo las condiciones políticas del momento. Según ella, la teoría recibe otro papel, uno nuevo en lo que se refiere a las relaciones entre lo social y lo literario/cultural. ${ }^{8}$

\section{2}

Hablar de "condiciones políticas" del momento es referirse a un escenario muy fluido. Jean Franco tenía en mente las situaciones de represión y el nuevo horizonte que se estaba abriendo. Me refiero a los procesos de redemocratización. Las teorías de Gramsci y de Bourdieu fueron recibidas, los planteamientos postestructuralistas se abrieron camino. El efecto sobre las Universidades, los centros productores de conocimientos sociales (FLACSO, CEBRAP, CENES) es notorio. Son notables, por ejemplo, los cambios en la Universidad de Buenos Aires, donde durante "un corto semestre de felicidad" (régimen Cámpora), Josefina Ludmer había explicado en 1973 a Derrida. En 1983-84 los intelectuales que habían tenido que desarrollar su actividad en el mundo editorial, en revistas, en cursos privados, entraron en grupo y realizaron cursos masivos y casi de choque para la reactualización de veinte años, más o menos. Lo mismo pasó en el Brasil, en donde las universidades (ejemplo: la escuela de Antonio Candido en São Paulo) habían representado un bastión democrático basado en premisas marxistas de los años sesenta. Después de 1982 y de verás desde 1985 se hizo poco a poco campo libre para otras concepciones.

Redemocratización sí. Pero al mismo tiempo, 1982 es el año de la más grande e inesperada crisis financiera, económica, en Latinoamérica, con la que el nuevo horizonte abierto de la liberación política y social fue puesto por completo en cuestión y las ilusiones de soberanía, modernización, nación independiente, desarrollo industrial completo, liberación nacional se desplomaron. Democracia, pluralismo y consenso son los conceptos-guía que se impusieron junto a un sentimiento de fuerte desencanto (Rincón 1985:108). (A la vuelta de la esquina esperaba la modernización neoliberal como parte de la nueva fase de la globalización).

A comienzos de los años ochenta la ciudad, con los nuevos problemas surgidos y los nuevos fenómenos culturales (desterritorialización de la cultura, hibridaciones entre repertorios incomunicados) pasó al centro de los intereses científicos con la temática general de la "cultura popular urbana". La ciudad se convierte en el campo de problemas más discutido, en objeto conjunto de investigación de diversas disciplinas. Carlos Monsiváis fue el primero en llamar la atención sobre las nuevas formas de la cultura urbana en relación con la cultura popular y el desarrollo de los medios masivos como un proceso de gran parte del

\footnotetext{
${ }^{8}$ Véase Jean Franco, "Trends and Priorities for Research on Latin American Literature", en Ideologies \& Literature 16 (1983) 107-120.
} 
siglo XX. ${ }^{9}$ La ciudad letrada de Ángel Rama apareció en 1984, después de su trágica muerte. El libro, sin redacción completa ni version final de sus partes, es sin embargo sintomático para la situación de Rama al entrar los ochenta, de su búsqueda de nuevos instrumentos conceptuales para la descripción de la historia y del presente. Entrega un importante aporte a la historia de los intelectuales y propone un diagnóstico velado sobre la historia inmediata. Decisivo en él, si se lo compara con su libro de resumen sobre la hipótesis modernizadora de la transculturación narrativa, ${ }^{10}$ es la conjunción de impulsos que recibió de distintos campos. Es obvio que después de șu amistad con José Luis Romero, fue determinante para Rama su encuentro con Richard Morse, el conocimiento de sus trabajos sobre la modernización de São Paulo, y el contacto de lector que Rama tomó con las investigaciones de los historiadores franceses de las mentalidades y los trabajos de Raymond Williams sobre la ciudad y el campo en la literatura inglesa. En la historia de las mentalidades descubrió la imagen de la ciudad "letrada" en el paso entre el final de la Edad Media y el Renacimiento. Un centro comercial, administrativo, humanista que existe como una isla, en medio de un océano de oralidad, paganismo y actividad agraria.

Un paso más allá de La ciudad letrada ya nos encontramos de lleno en el cambio de paradigmas de la segunda mitad de los ochenta, del que tanto se hablará al final de esa década y el comienzo de la actual.

Fue sobretodo la crítica y las teorizaciónes feministas, con lecturas y otras formas de escritura crítica, las que propusieron nuevos planteamientos y marcaron otros rumbos. El ensayo de Jean Franco "Apuntes sobre la crítica feminista y la literatura hispanoamericana" (1986) descifró ese fenómeno. Luego su libro Plotting Woman. Gender \& Representation in Mexico (1989), lleva la crítica feminista decididamente mas allá de la ginocrítica y las teorías de la escritura femenina, hacia los planteamientos de la cuestión del género, para presentar así un estudio ejemplar sobre el aporte de las mujeres a la modernización de un país. Que las nuevas investigaciones se concentraran en la época colonial es, por otra parte, resultado del cambio revolucionário impulsado por Walter Mignolo y Rolena Adorno, sobretodo: el abandono del campo de estudios definido por la noción anacrónica de "literatura colonial" al estudio y análisis de los "discursos coloniales"."

Esencial para el nuevo fenómeno de la crítica feminista, los planteamientos de género y los abordajes transdisciplinarios es el reclutamiento de estudiantes-mujeres desde los años setenta. ¿Acaso la fuerte presencia de críticos y especialistas desde finales de los ochenta no permite hablar tal vez de un reemplazo de filiaciones patriarcales por filiaciones matrilineales? En todo caso, la presencia de esas nuevas figuras en cátedras de gran prestigio en las universidades más cotizadas en los Estados Unidos, y en universidades latinoamericanas de influencia internacional, no puede ignorarse. Se trata ante todo de mujeres que publican libros muy notables, reorientando la investigación y que renuevan como pocos las formas

\footnotetext{
${ }^{9}$ Carlos Monsiváis 1978, "Notas sobre la cultura popular en México", en Latin American Perspectives 1 (1978) 98-118.

${ }^{10}$ Sobre ese libro y el rebasamiento de esa hipótesis por las teorías de la heterogeneidad, ver Friedhelm Schmidt, “¿Literaturas heterogéneas o literatura de la transculturación?" en el tomo ya citado de Nuevo Texto Crítico 14-15, 193-199.

"Rolena Adorno, "El sujeto colonial y la construcción cultural de la alteridad", en Revista de Crítica Literaria Latinoamericana, 28 (1982) 55-68.
} 
de escritura crítica. Pienso, por ejemplo, en el libro El genero gauchesco: undiscurso sobre la patria (1988) de Josefina Ludmer, en donde las cuestiones de la nación, y la ley, tan decisivas en los noventa, se plantean por primera vez plenamente. Con ese libro la noción de patria tiene un tratamiento radical que antes no había conocido. ¿En dónde reside esa radicalidad? Piénsese que el libro no es ni un tratado, ni un manual, ni un libro sistemático. Se pone en forma resuelta al borde del comentario paródico deconstructivo de un siglo de historia de crítica y apología en torno a la gauchesca. Notable en ese contexto es encontrar por eso que la mejor forma de la teoría literaria es la ficción. Esto que digo a propósito del bello libro de Josefina Ludmer, vale también para otros textos de mujeres, y para sujetos con "múltiples identidades", textos surgidos en espacios limítrofes, de frontera, y para formas de crítica como las que practica Carlos Monsiváis.

A fines de los ochenta y comienzos de los noventa aparecieron una serie de importantes contribuciones que pueden verse ya como resultados plenos del cambio de paradigmas. La primera, la relectura modelo de Doris Sommer de las novelas con heroínas de los cánones nacionales del XIX, Foundational Fictions: The National Romances of Latin America (1991), en términos de invención-construcción de proyectos de nación, como "ficciones fundacionales", y con la óptica de la cuestión poscolonial clave: "el fracaso histórico de la nación para constituirse a sí misma". ${ }^{12}$ El libro de Mary Louise Pratt Imperial Eyes: Travel Writing and Transculturation (1992) es uno de los ejemplos más espectaculares de la transformación en la investigación de los relatos (exotistas) de viajeros, la exploración del deseo y de las capacidades de lectura transdisciplinaria (posesión sexual-mirada/dominio colonial). Memory and Modernity (1991) de William Rowe y Vivian Schelling, como resumen y nuevo punto de partida en el debate sobre cultura popular, la investigación de Martin Lienhardt La voz y su huella (1989), A sátira e o engenho (1989) de João Adolfo Hansen, gran estudio sobre retórica, autor y autoría de los discursos barrocos, las contribuciones de Walter Mignolo al debate sobre canon y corpus, la letra y la geograficidad de lenguas, culturas y conocimiento y de John Beverley sobre literatura testimonial, más que mostrar el point of no return de la investigación, son resultados positivos de largo alcance. Algunos de esos muy destacados críticos y teóricos tomaron parte en 1991 en el Simposio de Berlín, cuyos resultados pueden verse como "agenda setting del futuro de la crítica" (Silviano Santiago) y la lectura de sus contribuciones lo confirma. ${ }^{13}$

En 1989 Desencuentos de la Modernidad en América Latina, de Julio Ramos, planteó un hecho esencial: con los escritores modernistas — con el caso de Martí como ejemplola autoridad de la literatura moderna radicó en un punto: la resistencia a los impulsos —- "los flujos"- de la modernización. Su lectura de "Nuestra América" como "Arte del buen gobierno", marcó un hito. Porque ése es el momento en que el debate sobre el posmodernismo

\footnotetext{
${ }^{12}$ Ranajit Guha, Preface, en Ranajit Guha y Gayatri C. Spivak (eds.), Selected Subalterns Studies (Nueva York: Oxford University Press, 1988) 43.

${ }^{13}$ Véase el tomo ya citado Nuevo Texto Crítico 14-15 (1995) y la encuesta internacional sobre la situación de la crítica literaria documentada en Revista de Crítica Literaria Latinoamericana, 31-32 (1990).
} 
en América Latina, iniciado como tal en el Brasil en 1984-1985 (Rincón 1995:107-134), en el que los artículos de Carlos Rincón y George Yúdice del Coloquio de Dartmouth en 1988, ${ }^{14}$ tuvieron inmediatamente influencia, se orientó de manera "decidida" hacia las teorías de la cultura, y la cuestión de las relaciones modernidad-modernización-modernismo tomada de Marshall Berman como tema de las ciencias sociales, fue dejada atrás con el libro del antropólogo Néstor García Canclini, Culturas hibridas. Caminos para entrar y salir de la modernidad (1990). Ese libro de resumen del debate entre los científicos sociales fue escrito en busca de un método y de caminos para salir de su propia crisis, ${ }^{15}$ lo mismo que con Una modernidad periférica: Buenos Aires 1920 y 1930 (1988), Beatriz Sarlo salió de su crisis como crítica. ${ }^{16}$ Esos trabajos, los de investigación de la comunicación desde la cultura de Jesús Martín Barbero, De los medios a las mediaciones. Comunicación, cultura y hegemonia (1987); Procesos de comunicación y matrices de cultura. Itinerario para salir de la razón dualista (1989), y los aportes de la investigación de historia y crítica literaria, hacen que hoy por hoy, como escribe Carlos Rincón, "el análisis y la teorización de los nuevos procesos culturales y la teoría cultural son el terreno por excelencia del debate sobre lo posmoderno en Latinoamérica, o para ser más preciso: la forma más actual de enfrentar la discusión y el diagnóstico sobre la contemporaneidad" (Rincón 1995:226-227). ${ }^{17}$

Entre esos libros de Martín Barbero, García Canclini y los trabajos de Sommer, Pratt, Rowe y Schelling había ocurrido un hecho de inmensa transcendencia: el fin de la guerra fría, la disolución del bloque de países socialistas, y con esto el auge de los procesos característicos de "la nueva fase del proceso de globalización" (Rincón 1995:103-105, 164165), entre ellos la cultural globalization. ${ }^{18}$

\section{4-1995}

En 1994 apareció el importante libro de Antonio Cornejo Polar Escribir en el aire. En 1995 Michigan University Press publicó el notable libro de Walter Mignolo The Darker Side of Renaissance. Literacy, Territoriality and Colonization y en Colombia se publicaron las dos primeras ediciones del libro de Carlos Rincón. Son libros de madurez teórica latinoamericana y es ese contexto el que hace "esperado e inesperado" el libro de Carlos Rincón, volviendo a la observación de Erna von der Walde. Con dos leitmotiv se celebra el éxito de La no simultaneidad de lo simultáneo: el libro se dirije igual a los especialistas y al público amplio (estudiantes, lectores nuevos, lectores cultivados), tiende a abolir el

\footnotetext{
${ }^{14}$ Publicados en la Revista de Crítica Literaria Latinoamericana, 29 (1989).

15 Jean Franco, "Border Patrol"; John Kraniauskas, "Hybridism and Reterritorialization", en Travesía 2 (1992) 134-142 y $143-151$.

${ }^{16}$ Véase Jorge Ruffinelli, "Beatriz Sarlo en Stanford. En torno a Buenos Aires: Una modernidad periférica", en Nuevo Texto Crítico 6 (1990) 157.

${ }^{17}$ Véase también Carlos Rincón, "Die neuen Kulturtheorien: Vor-Geschichten und Bestandsaufnahme". En Birgit Scharlau (ed.) Lateinamerika denken. Kulturtheoretische Grenzgänge zwischen Moderne und Postmoderne (Tübingen: Gunter Narr Verlag, 1994) 1-35.

18 Véase Anthony Giddens, The Consequences of Modernity (Cambridge: Polity Press, 1990); Volkmar Blum et al.(eds.), Globale Vergesellschaftung und lokale Kulturen (Frankfurt/M: Vervuert Verlag, 1992).
} 
conflicto entre Universidad y vida literaria y cultural, como opinan Luis Fayad y Hugo Niño. ${ }^{19}$ Al otro leitmotiv: "una relación de amor" del lector, le hace eco la editorial al incluir una opinión de Raymond Borgmeister, de su artículo "Lo que usted siempre quiso saber sobre el posmodernismo pero no se atrevía a preguntarlo", en la contraportada de la segunda edición: "la relevancia teórica, social, de un libro de visión panorámica, de introducción y al mismo tiempo de despeje de horizontes, de audaz reorientación como éste es elevada. El libro de Rincón despierta en el lector algo que no se siente por los libros de teoría sino por la literatura: una relación de amor". Lo notable es que la editorial suprime el desarrollo paradójico que le da Borgmeister a esa tesis, como receta para leer teoría: "Este es un problema complejo porque si el amor fuere una relación desinteresada, transparente, pura, pues no habría mejor relación con el libro. Pero naturalmente el amor, como escribió Jonathan Culler, es justo lo opuesto: una relación oscura, interesada, deseante, inconocible sin identificación, fetichización, transferencia, sadomasoquismo, regresión, agresividad. La pertinencia del libro se funde con el poder transferencial de esa forma de amor que inspira. Su importancia notable en lo teórico, lo social, lo político pasa por una relación deseante del lector".

El comentario de Borgmeister me parece exacto, su explicación se recubre sorprendentemente con nuestra propia experiencia de lectora de los análisis sobre García Márquez, Fuentes, Rodríguez Juliá y del libro en general, es convincente. Yo agregaría que en ese género de afecto-efecto se encuentra lo "posmoderno" del libro de Carlos Rincón. Decisivo es que la comprensión de la teoría ha cambiado fundamentalmente. No es una abstración, ni una especulación, ni una generalización. En cuanto reflexibilidad, con la deconstrucción de las posiciones del "observador teórico" que se pretende objetivo y firme, y de la "función representacional de la teoría" como dominio ejercido sobre un mundo de objetos, la edificación de la teoría se practica ahora en una forma completamente distinta. La práctica de la crítica cultural y de los estudios culturales se basa en esta mutación. El trabajo de Carlos Rincón se podría comparar, en el sentido de contrastar, sobre todo con el de las crónicas y ensayos de Carlos Monsiváis. Son las dos caras de la misma medalla: Carlos Rincón sigue el camino de los análisis concretos que conllevan la construcción de redes entre el discurso académico y el discurso público. Esto significa moverse en el campo de tensión entre cercanía a los fenómenos y procesos, referencia a su construcción y desconstrucción de sus modelos de conceptualización e interpretación, lo que equivale a describir y analizar sin renunciar a hacer teoría, mientras Carlos Monsiváis se sitúa en una situación de cercanía e inmersión completa en los fenómenos, por fuera y más allá de la praxis académica, y se substrae en buena medida de las formulaciones teóricas. De los resultados más notables de esa praxis en los límites del libro de Carlos Rincón-que lleva a establecer diversos códigos y sobre todo a un trabajo de traducción y mediación a través de las disciplinas- es de lo que son ejemplo los análisis de debates y de textos. Es de lo que también da cuenta, como intenté mostarlo al principio, la portada y el trabajo sobre las imágenes en el libro. Veamos esa praxis en más detalle y con ella algunas de las tesis principales del libro.

${ }^{19}$ Véase Luis Fayad, "La literatura posmoderna en Latinoamérica", en Gaceta 28 (1995) 10-12; Hugo Niño, "Lo postmoderno: Cuando la simultaneidad no es simultánea", en Magazín dominical de El Espectador (Bogotá, 2 de julio 1995). 


\section{UNA NUEVA CARTOGRAFÍA}

Proponer la formula del descentramiento de lo posmoderno para marcar la dirección del trabajo y como posible estrategia de Carlos Rincón no significa ignorar el debate posmoderno o, como se dice, sacarle el cuerpo. En esa forma el capítulo inicial "El incontenible ascenso del posmodernismo" presenta en su última parte "En Latinoamérica: debates inimaginables, rituales de purificación" un muy exacto y conciso balance de las distintas etapas, en la que no falta una historia de los usos de la noción. Son en primer lugar textos de Borges, la figura fundacional y legitimatoria (Rincón 1991:247) y sobre todo de García Márquez, los que a finales de los sesenta y comienzos de los setenta sirvieron de modelos a la ficción norteamericana posmoderna, que a su vez sirvió de base para constituir luego la idea de cultura posmoderna, de acuerdo con el modelo suministrado por ella. Esos textos fueron así elementos de construcción de la teoría (en los setenta) y de las teorías homogenizadoras sobre la posmodernidad (en los ochenta) en los Estados Unidos y en Europa. Más decisivo que la celebración del nuevo arte narrativo posmoderno es - según Carlos Rincón - la determinación del posmodernismo como hecho discursivo y de los conceptos de posmodernismo (posmodernismos) y posmodernidad de acuerdo con dos enciclopedias de textos primarios y secundarios de importancia. Posmodernismo: entre 1959 y 1979 se bosquejó una tipología de categorías y conceptos de análisis y descripción de técnicas, convenciones y características para diferenciarlas de las de lo moderno, en los campos de la producción de ficciones y después de artes visuales, arquitectura y vida cotidiana. Posmodernidad: después de 1979 ese terreno de empleo se amplió sobre todo para poder pensar el "pos" como "inversión-apropiación de la modernidad" y de esa manera marcar diferencias con los conceptos de espacio, tiempo, sujeto e historia ( de la "serialidad cronológica y los períodos homogéneos sucesivos") de la modernidad. Como estrategia de análisis y descripción de este segundo sentido epocal, la posmodernidad se concibió como re-consideración, re-escritura y re-inscripción de la modernidad (Rincón 1995: 48).

Con esto entramos al segundo capítulo amplio: "Reescribir lo que no se escribió". Aquí está expresada en el análisis de textos literarios y de procesos arquitectónicos pero sobre todo urbanísticos (la prueba del nueve del modernismo arquitectónico en Latinoamérica), lo que descifré en el examen del tratamiento gráfico de la portada y en la exégesis del título: subrayar la diferencia frente a los análisis y las teorizaciones posmodernas. Es de destacarse también el subcapítulo "Estilos de teoría y diversidad de desafíos" que ofrece una nueva serie de reflexiones y tesis sobre la problemática del "Proyecto de lo moderno en sus límites" y de esa manera una forma de situar al Proyecto Moderno dentro de otros marcos referenciales. A Carlos Rincón le interesa por eso la pregunta concreta de por qué el Proyecto Moderno llega a sus límites, con lo que abre el debate modernidad-posmodernidad según cuatro aspectos: 1) las diversas teorizaciones postmodernas respoden al imperativo conceptualizador de pensar el presente y hacer surgir el ahora, con su nueva configuración del campo cultural. En esas teorizaciones, que resultan una fuerza problematizadora en las sociedades occidentales, fluyó la asimilación de las formas de significar de las ficciones latinoamericanas (...); 2) el rechazo de tornar al Otro en lo Mismo ha fungido como divisa del posmodernismo. Sus semióticas fetichizaron la diferencia, el Otro, la alteridad. Pero en esa asimilación, en el camino hacia la construcción 
de marcos epistemológios y discursivos para formular problemáticas teóricas, el posmodernismo excluyó las especifidades culturales, lo propio de las políticas de la representación de las ficciones latinoamericanas, y con ello las teorizaciones -incluida la del ahora realizadas en ellas. (...); 3) la restitución y descubrimento de lo anulado y reprimido por los enfoques posmodernos y por el Proyecto Moderno en Latinamérica, ha basado por la reinscripción de esas ficciones en el contexto de la cultura latinoamericana actual. Esta reinscripción supone un desplazamiento, pues las viejas teorías, historias, convenciones acerca de esa cultura ya han dado lo que podían dar, mientras las teorizaciones culturales posmodernas se han revelado normativistas y excluyentes; 4) el diálogo con esas teorías y conectándose con un discurso que se ha ignorado, el discurso poscolonial - un proyecto asimétrico, con estrategias y presupuestos distintos al posmodernismo- las nuevas teorizaciones culturales latinoamericanas pueden contribuir a replantear (...) el debate modernidad-posmodernidad (páginas 79-80).

Tenemos así la propuesta de una pauta reflexiva que puede conducir al cambio de los términos del debate modernidad-posmodernidad y a rebasar sus limitaciones.

En los ensayos escritos sobre el libro de Carlos Rincón se ha hecho referencia a sus tesis sobre representación ("El territorio y el mapa: Para qué metaficción?) y sobre estrategias narrativas en el abordaje del discurso de la nación ("Intertextualidad, Pastiche, Alegorización"). Luis Fayad alude a sus tesis sobre "la nueva fase de la globalización", la fase de la aceleración y de las mutaciones actuales, que traen como consecuencia el aumento de las "independencias locales" y "las interdependencias globales". Quiero subrayar uno de los "cambios principales" a uno de los cuatro niveles que Carlos Rincón distingue de los efectos de la globalización en esta nueva fase, que es decisivo para la nueva cartografía. Se refiere a las construcciones de identidad, construcciones de sujeto y de posición de sujeto en esta nueva etapa. Se trata, en concreto, de la aparición de nuevos actores sociales y la constitución de nuevas identidades (colectivas), dinámicas o fluidas y múltiples. Con la mirada puesta en la cultura y la política emergente en donde se articulan de nuevas formas los intereses indígenas y campesinos - notoriamente en los casos de Guatemala, Colombia, Ecuador, Bolivia y México-, se está abordando la articulación de sujetos poscoloniales. Carlos Rincón no está hablando, naturalmente, de nuevos héroes, sino de sujetos "fuertes", en sentido estratégico-táctico. La acción y el discurso de esos nuevos sujetos y grupos son paralelos y están directamente unidos a nuevos planteamientos en el campo de la investigación, como "la lingüística afro-americana, la etnohistoria, la teoría literaria postestructural, la antropología visual, las nuevas ficciones historiográficas, en donde se plantean cuestiones de "esclavitud y subalternidad"' (Rincón 1995: 104).

\section{GLOBALIZACIÓN Y POSMODERNIDAD}

El capítulo final lleva a los discursos y a las sociedades de América Latina lo analizado y problematizado a lo largo de todo el libro, para entrecruzarlo e interconectarlo. La reconstrucción muestra que el ingreso latinoamericano en dos debates decisivos internacionales - sobre el posmodernismo, sobre el poscolonialismo- tiene lugar con algún retraso y muchas vacilaciones, a pesar de que en ambos casos no faltaban contribuciones esenciales. Finalmente - es la argumentación de Carlos Rincón-la problematización por 
distintas vías del Proyecto Moderno, del modelo normativo de modernización y de las formas de ciencia y teorización unidos a ella, ha llevado a la posibilidad de re-escribir (reinscribir) ese Proyecto. Esto es válido para las teorizaciones latinoamericanas muy recientes que trabajan los conceptos de "heterogeneidad" e "hibridación". Pero al mismo tiempo se ponen de relieve las dificultades o la imposibilidad, enfrentados a la velocidad de los cambios, de teorías sistemáticas.

Los límites de las conceptualizaciones y de la teorización se dejan ilustrar muy bien justamente en el caso del concepto de "hibridación" y su operacionalidad. La corta histórica que hace Carlos Rincón (páginas 207-208) de lo híbrido, parte de su aparición, a partir de las teorías postestructuralistas y de Bajtin, en la escena artística norteamericana para describir, a principios de los setenta prácticas artísticas emergentes posmodernas y más tarde, paralelamente, en la teorización de la arquitectura posmoderna. Después Homi K. Bhabha a principios de los ochenta hizo fructífero el concepto "hibridación" en el debate poscolonial para la problemática de la representación colonial. Tzvetan Todorov acuñó en 1986, partiendo de Bajtin a quien ha comentado en un libro completo, el término "culturas híbridas". El libro de ensayos de Néstor García Canclini, finalmente, corresponde en Latinoamérica al cambio del paradigma del "mestizaje" por la "hibridación", paralelo al debate multicultural norteamericano. Como estrategia para el rebasamiento de un esencialismo, identidad como concepto ontológico, esa operación no puede ser más alabada. Pero como concepto analítico unido a la visión antropológica de la cultura carece de ductibilidad - la que posee en el análisis literario y artístico, interesado en estrategias y mecanismos - cuando se asimila "hibridación" y "reconversión", de modo que no puede dar cuenta analítica de fenómenos de constitución de identidad sobre la base de continuas negociaciones o cambios permanentes. "Capital cultural" y "reconversión" son anteriores a la nueva fase de la globalización, donde surge el fenómeno de las "corrientes de capital cultural" y del "capital multicultural".

\section{POSMODERNISMO O POSCOLONIALISMO}

La atención es orientada a la pregunta decisiva: ¿qué diferencia lo posmoderno de lo poscolonial? ¿Se trata de dos agendas distintas que no se identifican y que al mismo tiempo se tocan, sin recubrirse con las agendas latinoamericanas? Mientras el posmodernismo se debate desde hace treinta años, el poscolonialismo es un fenómeno más que reciente. Aquí tenemos dos vertientes, literatura poscolonial y textos teóricos, que giran en torno al análisis del discurso colonial y la resistencia (Edward W. Said, Homi K. Bhabha, Gayatri CH.Spivak son los representantes más citados por Carlos Rincón). Para la literatura poscolonial son ejemplares "ficciones hibridizadas" como las de García Márquez, Fuentes, Borges, la literatura del boom, textos que en las literaturas de los antiguos imperios coloniales y las nuevas diásporas son objeto de apropiaciones que propician la reorientación que marca el prefijo pos en poscolonial. Esas literaturas encontraron desde finales de los setenta un modelo en "el realismo mágico" (Rincón 1995: 231-232). En cuanto a la segunda pregunta introducida, no hay más remedio y ésa es mi forma de concluir sin concluir: hay que leer el libro de Carlos Rincón y debatirlo. 